\title{
LA PRIMERA DÉCADA DE LA REVISTA CHILENA DE LITERATURA: ENTRE LA UNIDAD POPULAR Y LA DICTADURA MILITAR
}

\author{
Marcela Rosas Lira \\ Universidad de Chile \\ Santiago de Chile, Chile \\ marcelitarosas@hotmail.com
}

RESUMEN / ABSTRACT

Este artículo revisa la primera década de la Revista Chilena de Literatura (1970-1980), periodo en el que esta publicación manifiesta notorias modificaciones respecto a sus propósitos fundacionales. Lo que se realiza es una lectura de algunos artículos sobre autores y obras literarias chilenos, en la cual se identifican e interpretan los cambios teóricos y metodológicos presentes en dichos artículos y la incidencia que tanto la Unidad Popular, como el golpe y la dictadura militar tienen en tales modificaciones. Ante los cambios evidenciados, se evalúa la relación que tuvo la revista con su contexto y las estrategias que utilizó para resituarse en el panorama académico chileno durante la dictadura acercándose con ello a formatos propios del circuito de comunicación científica.

Palabras clave: Revista Chilena de Literatura, revista científica, crítica literaria, Unidad Popular, dictadura.

\section{THE FIRST DECADE OF REVISTA CHILENA DE LITERATURA: BETWEENTHE UNIDAD POPULAR AND THE MILITARY DICTATORSHIP}

This article reviews the first decade of Revista Chilena de Literatura (1970-1980), a period in which this publication shows notable changes from its foundational purposes. Through the reading of some articles about Chilean authors and their literary works, it has been possible to identify and interpret theoretical and methodological changes present in these articles, along the impact that both the Unidad Popular as well as the coup and the military dictatorship played in these changes. Taking into account these changes, the relation that the magazine had with its context and the strategies to re-position itself in the Chilean academic landscape in dictatorship are evaluated, thereby approaching formats likely to appear in fields related to scientific communication. 
KEYWORDS: Revista Chilena de Literatura, scientific magazine, literary criticism, Unidad Popular, dictatorship.

\section{INTRODUCCIÓN}

Frente al panorama actual de las revistas académicas, sus sistemas de evaluación, sus formatos de divulgación y su incorporación a grandes bases de datos internacionales, cabe preguntarse si es posible abordar este tipo de publicaciones desde su relación con su contexto inmediato y los eventuales diálogos e intervenciones que establecen con su presente. Más específicamente, y respecto a las revistas académicas ligadas al ámbito de las humanidades, surge la inquietud de entender qué sucede con estas áreas y su vinculación tanto con el entorno social, como con el campo científico y el requerimiento de difundir los resultados de sus investigaciones en formatos provenientes del campo de la ciencia como es el caso del paper.

El presente artículo se propone como objetivo ofrecer un panorama de la primera década de existencia de una revista académica centrada en la crítica y los estudios literarios, la Revista Chilena de Literatura (en adelante $R C h L$ ), la cual, fundada en 1970, se mantiene hasta la actualidad. Lo que se pretende es reconocer los diálogos que esta publicación tiene con la agitada coyuntura política, social y académica de la década de los setenta y cómo este aspecto incide en su paulatino acercamiento al circuito y a las formas de comunicación propias del ámbito científico.

La hipótesis que orienta el análisis es que, si bien esta revista constituye una publicación académica especializada, tanto en sus primeros tres años previos al golpe militar, como en los años posteriores a éste, establece múltiples y complejas relaciones con diversas esferas de su contexto inmediato, incluso cuando este entorno se torna hostil y represivo, momento en el cual la necesidad de validarse dentro del ámbito académico y científico constituye una estrategia para resituarse dentro del constreñido campo cultural chileno. Todo lo anterior, aunque no se reconoce en una línea editorial explícita de la publicación, es posible evidenciarlo en los enfoques teóricos y metodológicos con que se aborda el fenómeno literario en los artículos de la $R C h L$, en especial, aquellos que estudian autores y obras literarias chilenos. 
En relación con el corpus analizado, se abordan algunos de los artículos sobre autores y obras literarias chilenos pertenecientes a los quince primeros números de la $R C h L$ publicados entre 1970 y 1980, a través de los cuales es posible reconocer los principales enfoques teórico-metodológicos con que es abordada la literatura nacional. Para enmarcar este análisis se profundiza en bibliografía que permita dar cuenta, en términos generales, del campo académico chileno de principios de los setenta y de los cambios que experimenta tras el golpe militar, además del proceso de modernización de la crítica literaria chilena iniciado a principios de 1960 y finalizado abruptamente en septiembre de 1973.

Lo que se realiza es una interpretación tanto de la relación entre el contexto político y académico chileno y las modificaciones que experimenta la revista, como entre estas modificaciones y el eventual acercamiento que propician a los formatos y al circuito de comunicación propio de las comunidades científicas. La particularidad del abordaje radica en ubicarse en un terreno donde se cruza el pasado y el presente de la crítica literaria académica y de sus formas de divulgación en la medida en que la comprensión del rol de esta publicación en medio del campo académico de los setenta lleva a reflexionar acerca de cuál es el que cumple en la actualidad.

\section{PERSPECTIVAS ACTUALES EN TORNO AL ESTUDIO DE LAS REVISTAS}

Durante las últimas décadas, las revistas han comenzado a ser estudiadas desde distintos ámbitos disciplinarios, para los cuales se han convertido en objetos de interés precisamente en la medida en que se las enfoca desde la relación que establecen con la coyuntura histórico-cultural en que fueron concebidas. A partir de esta mirada multidisciplinar, las revistas se perciben como "un espacio dinámico de circulación e intersección de discursos altamente significativos para el estudio no sólo de la literatura sino del análisis, la historia y la sociología cultural, la historia de las ideas y la historia intelectual, entre otros campos" (Schwartz y Patiño 647).

El análisis de la revista se amplía entonces más allá de la lectura de sus contenidos, para indagar en sus conexiones e incidencia en su presente, ya que, como señala Beatriz Sarlo, la expresión "publiquemos una revista", no consiste solo en reunir una serie de textos, sino que significa, en realidad, "hagamos política cultural" (9). Así, las revistas culturales y literarias, incluso las más especializadas, comienzan a ser entendidas como "textos preñados 
de contexto" (Beigel 110), en los que la reflexión en torno a la literatura se cruza con dimensiones ideológicas y/o estéticas que hablan de ese presente desde y para el cual la revista fue pensada y publicada.

Este planteamiento se ratifica en la medida en que las revistas culturales y literarias aparecen en su medio estableciendo temas y problemas, frutos no solo de un autor individual, sino de la decisión editorial de un conjunto de personas de poner el texto de ese autor, en una revista, un número y una ubicación determinadas. Es esta serie de decisiones la que hace de la revista un texto colectivo que busca abrirse paso e incidir en la cultura de su tiempo instalando en su presente determinados temas, al mismo tiempo que deja de lado algunos otros, lógica inclusiva y exclusiva, a través de la cual las revistas permiten conectarse con los modos de legitimación de nuevas prácticas políticas y culturales (Beigel 110). De aquí se deriva que las revistas sean concebidas simultáneamente como documentos de historia y como formaciones culturales colectivas que funcionan como agentes activos dentro del campo de la cultura.

Ahora bien, la intervención cultural realizada por las revistas no es una y la misma en todos los casos, sino que presenta diversas facetas según sea la porción del campo intelectual del que surja la publicación y los objetivos específicos que su grupo editorial tenga. Lo anterior es un aspecto a considerar en especial cuando se trata de publicaciones nacidas bajo el alero de una institución académica enfocada principalmente en tareas de investigación y producción de conocimiento, formando parte de lo que se conoce como revista científica. Definidas como una "publicación periódica que presenta especialmente artículos científicos, escritos por autores diferentes, e información de actualidad sobre investigación y desarrollo de cualquier área de la ciencia" (cit. en Mendoza y Paravic 30), las revistas científicas constituyen un importante vehículo de transmisión de los avances en la investigación de una disciplina y de comunicación entre los investigadores.

El campo de las ciencias aparece como un campo semejante a otros, puesto que también constituye un espacio de relaciones de fuerzas, en el que hay luchas e intereses propios de agentes e instituciones que ocupan lugares específicos en este entramado. Desde este punto de vista, sistemas como el de la evaluación entre pares o el uso de indicadores bibliométricos ${ }^{1}$ constituyen

La evaluación entre pares o peer review constituye un sistema de evaluación de artículos de revistas científicas, conocido también con el nombre de "arbitraje" o "juicio de 
formas específicas de interés, las cuales, de acuerdo al planteamiento de Pierre Bourdieu, nacen del hecho de que las prácticas científicas y su consiguiente enjuiciamiento están orientadas a la adquisición de validez y de autoridad por parte de los propios pares al ser ellos los que poseen las competencias y están en condiciones de acceder y evaluar su contenido (El campo 77).

$\mathrm{Al}$ entender la labor del investigador inserta en un campo científico, su práctica, lejos de ser desinteresada y neutra, es realizada con el afán de alcanzar validez y autoridad dentro de dicho campo, por tanto, "la idea de una ciencia neutra es una ficción" (Bourdieu, El campo 102). De este modo, el hecho de publicar los resultados de una investigación en una revista científica resulta ser tan importante como la investigación misma, pues implica un recurso estratégico, en la medida en que un investigador, al dar a conocer su trabajo, alcanza reconocimiento, es citado, sirve de fuente para otros estudios y otorga prestigio a la institución que representa (Valderrama 1-2).

\section{APARICIÓN DE LA REVISTA CHILENA DE LITERATURA EN MEDIO DEL CAMPO ACADÉMICO CHILENO: ENTRE LA REFORMA UNIVERSITARIA Y LA UNIDAD POPULAR}

Durante el año 1967, y dentro del contexto de una serie de reformas impulsadas por el gobierno de Eduardo Frei Montalva, en las universidades chilenas se gesta una visión crítica que percibe cierta inadecuación y estancamiento del mundo académico respecto a los cambios que se han dado lugar en el resto de la sociedad durante la década de los sesenta. Lo que se pretende es que "la universidad fuese centro activo de la vida cultural de la nación, sobre todo, un lugar de expresión de las vivencias culturales del pueblo para ponerlas en estrecho contacto con la cultura universitaria" (Casali 91). De la mano con lo anterior, se plantea la necesidad de renovación del conocimiento, dándole un

los pares", pues intervienen, casi siempre, dos especialistas que son designados árbitros o revisores del escrito original. En cuanto a los indicadores bibliométricos, estos consisten en datos estadísticos deducidos de los rasgos de las publicaciones científicas, los que incluyen una serie de conceptos cuantitativos, que, en su mayoría, apuntan a medir la visibilidad y el alcance de una revista científica partiendo de la lógica de que mientras más investigadores lean un artículo y lo citen, mayor impacto en la comunidad científica tienen el investigador y sus ideas. 
papel decisivo a la investigación y a la comunicación de sus resultados, todo lo cual deriva en el proyecto denominado Reforma Universitaria:

La Reforma Universitaria en Chile es el proyecto de transformación de las tradicionales estructuras de administración y docencia de los planteles universitarios, impulsado por el movimiento estudiantil rebelde, al que se sumó el conjunto de la comunidad universitaria progresista en los años 1967 y siguientes, con el fin de materializar cambios en el interior de los establecimientos universitarios, que tendieran a contactar a la $<$ universidad $>$ con la $<$ sociedad $>$, poniéndola a su servicio (Casali 89).

Respecto al impacto de esta reforma en la Universidad de Chile, uno de los planteamientos más relevantes es la necesidad de estructurar la universidad en razón del conocimiento y la cultura y no de las profesiones, haciendo de los departamentos unidades de investigación, docencia y extensión en un campo del saber que garantice la autonomía de la labor académica (Casali 94). En el ámbito específico de las humanidades, este énfasis lleva a que áreas especializadas como el Departamento de Español de la Universidad de Chile funde en 1970 una publicación académica centrada en la literatura chilena e hispanoamericana y los estudios literarios denominada Revista Chilena de Literatura.

Su fundador y primer director, el académico del Departamento de Español de la Universidad de Chile Cedomil Goic, en el discurso de presentación de la revista enlaza la publicación con la coyuntura universitaria del momento, señalando que "en el mejor espíritu de la reforma universitaria, esta revista es la manifestación de una decidida voluntad de extender y difundir el conocimiento de las letras nacionales y de nuestra realidad cultural" (párr. 2). De acuerdo con lo anterior, los propósitos iniciales de esta publicación se centran en divulgar estudios sobre literatura chilena e hispanoamericana e informar sobre la vida literaria nacional:

LA REVISTA CHILENA DE LITERATURA es una publicación del Departamento de Español de la Facultad de Filosofía y Educación de la Universidad de Chile, en Santiago. Está destinada, principalmente, a recoger estudios sobre literatura chilena e hispanoamericana y creaciones de autores vivos de estas literaturas; a reseñar y llevar un registro riguroso y completo de la producción literaria nacional, y a informar sobre los acontecimientos más importantes de nuestra vida literaria (párr. 1). 
Por otra parte, el año de fundación de la revista coincide con la llegada a la presidencia de la República de Salvador Allende Gossens, quien encabeza el proyecto conformado por la coalición de partidos de izquierda conocida como Unidad Popular. Este nuevo gobierno pretende que la actividad cultural se transforme en un agente revolucionario de fácil acceso para las masas trabajadoras, haciéndolas parte activa en la construcción de la autodenominada vía chilena al socialismo. De acuerdo con el programa allendista, esta incorporación de las masas se logra "tanto a través de un sistema educacional radicalmente transformado, como a través del establecimiento de un sistema nacional de cultura popular ... [que] estimulará la creación artística y literaria y multiplicará los canales de relación entre artistas o escritores con un público infinitamente más vasto que el actual" (27-28).

Sin embargo, para una porción del campo cultural chileno el rol del intelectual aparecería en este tipo de declaraciones solo como un mediador entre la alta cultura y la cultura de masas, quedando en entredicho su capacidad de gestión y creación cultural. Lo que se critica entonces es la asignación de un rol pasivo a la cultura vista como mero reflejo de factores objetivos como la economía y la política. Por el contrario, una porción de intelectuales de izquierda ${ }^{2}$ defienden una concepción más activa y autónoma que busca consolidar una cultura nacional que permita alcanzar el nivel de conciencia requerido para lograr un real acceso al socialismo (Canto 165-166).

Dando énfasis a la idea de una relectura crítica de lo nacional, ya puesta en discusión a partir de la Reforma Universitaria, se plantea la necesidad de vincular la labor intelectual con la formación de una cultura nacional (Casali 90) y con el descubrimiento de nuevas dimensiones la realidad chilena y latinoamericana a través de la renovación y emancipación del conocimiento. En esta línea, el mundo académico se hace partícipe desde el ámbito de la investigación, intentando articular la formación de una identidad nacional

2 Dicho grupo de intelectuales forma parte del Taller de escritores de Chile, compuesto por autores e intelectuales como Alfonso Calderón, Enrique Lihn, Poli Délano, Hernán Loyola, Luis Dominguez, Germán Marín, Ariel Dorfman, Waldo Rojas, Jorge Edwards, Antonio Skármeta, Cristián Huneeus, Federico Schopf, Hernán Lavín y Hernán Valdés. Como Taller de escritores, publica en 1970, en el último número de la revista Cormorán, dirigida por Enrique Lihn, el documento "Por la creación de una cultura popular y nacional", en el cual hacen frente a las concepciones que entienden la cultura como un reflejo pasivo del proceso revolucionario, proponiendo para los intelectuales y artistas el rol de gestores culturales. 
autónoma con los propósitos y las formas de divulgación propias de la investigación académica.

Dentro del área de los estudios literarios, ya desde mediados de los sesenta e inicios de los setenta, la crítica literaria chilena había comenzado a experimentar un proceso de modernización, entendido como un momento de renovación tanto de la crítica, como de la investigación literaria, que tiene a la universidad como eje y canal de difusión. En este marco, la fundación de la $R C h L$ responde a la necesidad de una relectura de lo nacional explorando la posibilidad de dar "expresión al movimiento renovador de la crítica y de la investigación literaria del Departamento de Español de la Universidad de Chile, cuyos profesores son conocidos en el país y en el extranjero por la nueva orientación dada a la crítica y a los estudios literarios" (Goic, párr. 4).

Bernardo Subercaseaux se refiere a este proceso de modernización de la crítica como el resultado obtenido "luego de casi una década de forcejeo entre las dos almas que habitan la crítica, el alma artística y el alma cientificista" (Historia "personal" 1). Así, en medio de cátedras, clasificadas como "impresionismo crítico" en las que se habla tanto del autor como de la obra, sin más sistema que la intuición, gusto, sensibilidad o personalidad del docente, se manifiesta una generación de recambio, en la cual profesores como Cedomil Goic representan la postura de los estudios literarios y de la crítica entendidos como un saber objetivo y sistemático (Historia "personal" 1).

Al tomar contacto con corrientes críticas europeas como el formalismo ruso o el estructuralismo del Círculo de Praga, Wolfgang Kayser, la fenomenología de Husserl o la escuela de Frankfurt, junto con disciplinas como la lingüística, se va en búsqueda de elementos teóricos y paradigmas de cientificidad teniendo como premisa la especificidad del discurso literario. De acuerdo con lo anterior es que, de las dos etapas de este proceso modernizador, la primera de ellas que va de 1960 a 1968, se caracteriza por el predominio de una visión de radical autonomía del fenómeno literario, privilegiando especialmente el texto por sobre cualquier apreciación externa o subjetiva sobre éste (Subercaseaux, Transformaciones 7$)^{3}$.

\footnotetext{
Sin duda, esta perspectiva inmanentista se da no solo en reacción al "impresionismo crítico" presente en las aulas universitarias, sino también a su predominio en la crítica literaria difundida en la prensa chilena, especialmente en el diario El Mercurio, de la mano de críticos como Alone (Hernán Díaz Arrieta) o Ignacio Valente (José Miguel Ibáñez Langlois). Ambos autores constituyen en ese momento voces autorizadas de gran importancia para las letras chilenas.
} 
La $R C h L$ aparece entonces tras una década en la que los estudios literarios aspiran a convertirse en un área del saber que, en consonancia con los planteamientos de la Reforma Universitaria, oriente su labor a la investigación, intercambio e interacción entre pares, siendo la fundación de una revista la ocasión propicia para el logro de estos objetivos, dando así expresión a las nuevas tendencias que los académicos del Departamento de Español de la Universidad de Chile asumen respecto a la crítica y los estudios literarios.

\section{A. ENFoQues teóRICOS Y METOdOLÓGICOS EN LOS ARTícUlos ENTRE 1970 Y 1972}

La fundación de la $R C h L$ en 1970 puede ser entendida como un corolario del proceso que se ha venido gestando durante toda la década anterior por parte de la crítica literaria chilena. Ubicada en lo que se ha llamado la segunda etapa el proceso de modernización de la crítica desarrollada entre 1968 y 1973, esta revista se enmarca en un momento en el que aparecen en la crítica corrientes afines a una comprensión contextualizadora que ofrece una perspectiva socio-histórica en la que el fenómeno literario y su análisis son entendidos como signos de un momento social e histórico que vive un proceso de cambio. Conjuntamente, hay también un uso ecléctico de corrientes europeas para ajustarlas a la situación nacional y latinoamericana (Subercaseaux, Transformaciones 7).

Dentro de los años comprendidos por esta segunda etapa, la $R C h L$ publica entre 1970 y 1972 un total de seis números, uno por semestre, agrupando tanto los números dos y tres, como el cinco y seis en un solo ejemplar publicados durante 1970 y 1972, respectivamente. La gran mayoría de sus textos (artículos, notas, reseñas) abordan distintos temas relacionados ya sea con los estudios literarios en general, como con autores y obras nacionales y latinoamericanos, siendo estos últimos ámbitos temáticos los de mayor presencia con énfasis en la literatura chilena ${ }^{4}$. Con respecto a los artículos, es posible evidenciar a través de los enfoques teórico-metodológicos utilizados, la presencia en la revista de las nuevas tendencias propias del proceso de

\footnotetext{
$4 \quad$ De un total de treinta y dos artículos publicados por la $R C h L$ entre 1970 y 1972 , doce de ellos tienen como tema autores u obras literarias chilenas, dos se enfocan en aspectos transversales a la novela y el teatro hispanoamericanos contemporáneos, mientras que los diecisiete restantes abordan autores u obras latinoamericanos de distintas nacionalidades.
} 
modernización experimentado por la crítica literaria respecto al tratamiento de la literatura chilena.

Ya en el primer artículo publicado en la revista, titulado "Poética del exordio en "La Araucana" del profesor de Cedomil Goic, se encuentra un análisis formal de los exordios de La Araucana, cuyo autor enuncia como propósito el "modesto empeño de leer la obra con una fidelidad al texto que abra camino para su existencia verdadera, más allá o más acá de las nieblas que se le han arrojado encima y, desde ya, sin ninguna pasión deformadora, sino más bien dejando que la singularidad de la obra se manifieste por sí misma" (Poética 6).

En este empeño se reconoce una perspectiva inmanentista que tiene al texto como centro del análisis evidenciándose algunos principios fundamentales de las corrientes de crítica literaria formalistas, las que al "colocar la obra en el centro de sus preocupaciones, rehúyen el enfoque psicológico, filosófico o sociológico... según ellos no se puede explicar la obra a partir de la biografía del escritor, ni partir de un análisis de la vida social contemporánea" (Todorov 12).

Más aún, el énfasis en dejar fuera cualquier "pasión deformadora" y abrir camino para la "existencia verdadera de la obra" se adscribe al propósito formalista de ir más allá de todo subjetivismo en la interpretación, pues para esta corriente "la ciencia académica que ignoraba enteramente los problemas teóricos y que utilizaba tibiamente los envejecidos axiomas tomados de la estética, la psicología y la historia, había perdido hasta tal punto el sentido de su objeto de estudio que su propia existencia era ilusoria" (Eichenbaum 24). De esta manera, Goic percibe que una obra tan fundamental para las letras chilenas como La Araucana ha sido leída por pocos y opacada por muchos a causa de lecturas que se han alejado de su singularidad ${ }^{5}$.

En una vereda muy distinta, se encuentran los artículos publicados en esta primera etapa por autores como Antonio Skármeta o Ariel Dorfman. En ellos, el análisis involucra en la interpretación literaria aspectos contextuales propios del momento en que el crítico escribe. A este respecto, dice Arnold Hauser que "cada crítica es esencialmente crítica del día y se emite desde el punto de vista de las condiciones respectivas" (609), con lo cual da a entender que en la crítica realizada desde una óptica sociohistórica, el autor juzga la obra

A este respecto, Goic señala varias corrientes críticas, entre ellas la neoclásica y la de espíritu nacionalista, las cuales han visto en la obra de Ercilla muchos defectos, impertinencias e insignificancias que opacan su valor (Poética 6). 
de arte desde una perspectiva sociológica y psicológicamente determinada (607). En esta línea, es que se reconoce en el análisis de Skármeta y Dorfman la presencia de elementos propios de la contingencia chilena vivida durante el gobierno de la Unidad Popular, tanto en la visión de mundo, como en los esquemas de interpretación de la realidad.

En el análisis literario realizado por Antonio Skármeta se establece una continuidad entre la obra y la sociedad en la que el estudio de los dramas se centra en su mensaje ideológico, reflexionando acerca de los conflictos de clase suscitados en medio de la sociedad chilena de ese entonces. Así, en el primero de los artículos donde se analiza el motivo del conflicto entre aldea y ciudad, el autor lo aborda a la luz de "los términos sociales en pugna según el esquema marxista" (El motivo 40). De acuerdo con este esquema, los elementos opuestos serían un mundo patronal interesado en que las cosas persistan en su orden y un mundo urbano poseedor de "la conciencia de los poderes del proletariado [que] cuando se une, establece una dinámica oposición política: explotadores y explotados" (El motivo 40), oposición que es vista desde una dimensión dialéctica en la que el proceso de concientización lleva a entender "la situación como limitada y susceptible de cambio" (El motivo 40).

En el caso de Ariel Dorfman, el segundo de sus artículos se titula "El patas de perro no es tranquilidad para mañana" y aparece durante 1970 en los números dos y tres de la $R C h L$. Teniendo como tema la novela Patas de perro de Carlos Droguett, quien obtiene el Premio Nacional de Literatura ese mismo año, Dorfman publica un bastante poco tradicional artículo cuyo título es, además, una especie de ironía y provocación frente al eslogan de la campaña presidencial del representante de la derecha chilena Arturo Alessandri que expresa que "Alessandri es tranquilidad para el mañana". El artículo de Dorfman presenta la novela de Droguett como todo lo contrario a este eslogan, lo que realiza a través de un estilo de escritura, cuya libertad formal y estilo personal lo acercan mucho más al ámbito del ensayo literario que a la objetividad y concisión del artículo científico.

Una de las particularidades más evidentes de este escrito es que Ariel Dorfman alude en él a su propia autoría, al lector de la revista, al medio en que publica y a sus propias circunstancias escriturales. De este modo, el eventual lector de la revista es mencionado como "el que ha pagado no sé cuántas lucas por leer este estudio en esta revista (a mí me la regalan)" (167) o, en un evidente guiño autocrítico, ironiza respecto a la seriedad de la revista y a las posibles interpretaciones de sus artículos: “¿Quién, quién es el que en este momento prepara fichas para clasificarnos? Unos cuantos 
lo leen, se publica en esta Revista Chilena de Literatura, de tapa funeraria, de márgenes tan exactos, nos leerán en Europa, en USA, miren las cosas que sacan estos bárbaros" (197).

En su análisis, Dorfman ve en Bobi, el niño con patas de perro que protagoniza la novela, una imagen representativa de los marginados del circuito socioeconómico capitalista y de todo lo que está en riesgo de perder su dignidad y convertirse en un producto del mercado, frente a lo cual manifiesta una concepción de la literatura como herramienta de denuncia social y emancipación cultural, dejando, sin embargo, en duda cuál es la labor del crítico en medio de este contexto. Hacia el final del ensayo, Dorfman actualiza estas visiones y tensiones al preguntarse por la utilidad del libro de Droguett, planteando si éste servirá para guardarlo, venderlo, palmotearle la espalda a su autor o clasificarlo desde la academia para que algún ensayista como él "demuestre su conocimiento y copie frases en su currículum... ¿Sirven para algo los críticos?” (El patas 197).

Mención especial entre esta diversidad de enfoques merece el artículo titulado "La escritura de la semejanza en Nicanor Parra" del teórico y docente de la Universidad de Chile, Federico Schopf, aparecido en los números dos y tres de la revista durante el año 1970. Presentado como parte de un libro mayor sobre Nicanor Parra, este artículo ofrece una comprensión del fenómeno literario que, al considerar al lector como parte del proceso de constitución de sentido, incorpora al análisis de la obra la dimensión estética, la cual "acontece como un momento de la existencia de los lectores reales. De este modo, tanto las imágenes como su estructura y sentido son proyectados por el lector sobre su propia vida" (44).

El autor establece, además, un diálogo crítico con las teorías literarias que sostienen la total autonomía e independencia de la obra, pues, con la apertura hacia el momento estético "se experimenta que la necesaria independencia o autonomía de la obra poética es un modo de dependencia, cuya perfección adviene en la verdad concreta de las imágenes y estructuras con respecto a una situación humana y singular" (La escritura 44). El artículo tiene como objetivo entonces evidenciar algunas de estas relaciones de dependencia, para así dar una concepción fundada de la antipoesía, proporcionando, de paso, fundamentos para las afirmaciones sostenidas en la bibliografía existente sobre la obra de Nicanor Parra.

El extenso análisis realizado se centra específicamente en el poema "Hay un día feliz" del libro Poemas y Antipoemas de Nicanor Parra publicado en 1954. Abordando distintos niveles del texto que van desde un análisis lineal, 
pasando por sus estructuras expresivas, comunicativas e ideológicas, el artículo evidencia cómo en este poema se intenta crear un mundo semejante al lejano mundo rural de la infancia al que el hablante desea regresar para resguardarse de la dureza del mundo y de la exposición al inefable paso del tiempo, regreso que desde el principio se sabe imposible.

Es así cómo el crítico señala que "los esfuerzos de este análisis y esta exégesis crítica nos harán ver claro que toda poesía auténtica abre mundo más acá de lo que directamente se expone ¿En qué sentido esta poesía, toda ella artificialmente construida, es auténtica? ¿Qué "abre"? (La escritura 57), la respuesta a esta pregunta radica en la apertura que el poema realiza para el lector respecto a la realidad y la temporalidad de la existencia. El intento por hallar un lugar de resguardo no es más que una manera de rehuir de "la experiencia insoportable de la temporalidad de la existencia y la experiencia de una sociedad represiva que deforma y obstaculiza las posibilidades reales de la plenitud del hombre" (La escritura 86).

Entre los procedimientos de análisis utilizados por el autor para efectuar la interpretación, destaca el hecho de leer la antipoesía a la luz de distintas tradiciones literarias y culturales que actualizan elementos de la tradición poética occidental, como, por ejemplo, el tópico de la vida como sueño y la imagen del río que va dar en la mar (aludidos en relación con la construcción de un mundo que solo puede ser aparentemente feliz, pero que en el fondo es desengaño) o la presencia de la ironía a la manera en que es efectuada por el narrador del Quijote, lo que es reconocido en el poema en el uso de la expresión "singular empresa" con la que el hablante lírico se refiere a su intento de retorno cuyo fracaso se sabe de antemano. Así entonces, para el crítico, los antipoemas introducen una modificación relevante en la poesía chilena e hispanoamericana en la medida en que su eficacia ya no descansa en la mera combinación de figuras literarias, sino que opera a partir de un contexto en que son emplazadas distintas tradiciones.

Revisados algunos de sus artículos, puede constatarse que los primeros números de la $R C h L$ aparecen en medio de un campo cultural en el que se cruzan diversos enfoques y posturas respecto al rol del intelectual, del arte y de la cultura. Los intelectuales se mueven en distintos ámbitos de acción conectando la actividad cultural ya con la esfera política, en la medida en que son partícipes de distintas iniciativas culturales de la Unidad Popular, ya con el mundo académico, publicando, por ejemplo, en revistas académicas como la $R C h L$. Frente a esta actividad y diversidad del campo cultural, es que puede entenderse la pluralidad de enfoques y estilos que se manifiestan 
en los primeros seis números de la publicación, dando lugar a esa sintaxis que, para Beatriz Sarlo, surge al poner en conjunto textos individuales en una revista, y que proporciona información sobre su propio tiempo.

\section{B. SilenCio y REAPARICIÓN DE LA $R C H L$ (1973-1980)}

Los tres años de la Unidad Popular, en especial los últimos, terminan siendo un periodo de crisis, agitación y radical polarización de la sociedad chilena, marcado por problemas económicos suscitados especialmente por la oposición de las clases conservadoras y más acomodadas al gobierno de Salvador Allende. En medio de esa coyuntura, la $R C h L$ deja de publicarse en la primavera de 1972. En palabras de su fundador, el profesor Cedomil Goic, con respecto a la situación de la publicación durante 1972 y 1973 señala que "en esos años no hubo manera de obtener fondos para la publicación hablando con el Decano y con el Rector de la universidad" (Re: Revista, párr. 1). Por lo tanto, puede inferirse que, en una primera instancia, las dificultades para la continuidad de la revista surgen ya antes de la ocurrencia del golpe militar y dicen relación con problemas de financiamiento.

Aproximadamente un año después del receso de la revista, acontece en Chile el golpe militar con el cual se da un drástico final al proyecto de la Unidad Popular. En medio de toda la convulsión social provocada por este hecho, la Universidad de Chile es profundamente intervenida, poniéndola incluso en manos de un rector uniformado quien enarbola como principal bandera de lucha el extirpar el "cáncer marxista" de la universidad como parte de la "operación limpieza" que el gobierno militar realiza a lo largo del país. Con lo anterior, muchos funcionarios y docentes son expulsados, lo que ocasiona que gran parte de los autores que publican durante los primeros años de la $R C h L$ abandonen la universidad e incluso el país, no reapareciendo en la escena cultural sino hasta fines de los ochenta y principios de los noventa con el fin del régimen militar y el retorno a la democracia.

Lo que viene entonces tras el gobierno de la Unidad Popular en Chile son diecisiete años de dictadura militar en los cuales la cultura experimenta un estancamiento y una reinterpretación a la luz de parámetros nacionalistas y neoliberales. Respecto al ámbito específico de la crítica literaria, a causa de las severas transformaciones implementadas en el ámbito académico, tanto las que implican maniobras represivas, como las orientadas a la implementación de un nuevo modelo social y económico de corte neoliberal, no solo se ve afectado el espacio en que se desarrollan los estudios literarios, sino que, 
además, incide en las formas de producción, difusión y recepción, provocando "la jibarización, la compartimentalización y la involución a microcircuitos de la crítica" (Subercaseaux, Transformaciones 15).

En medio de este complejo momento, la $R C h L$ reaparece en 1976, manifestando profundas diferencias respecto a los artículos publicados durante sus primeros años. Una de las modificaciones más evidentes surge en relación con el corpus literario sobre el cual se efectúan los análisis; así, si en sus primeros números la revista se aboca exclusivamente a autores y obras chilenas y latinoamericanas, esto es sustituido por el predominio de la literatura europea ${ }^{6}$. En cuanto a la literatura chilena, mientras que en su primera etapa la revista aborda de forma medianamente equiparada obras nacionales pertenecientes a los tres géneros literarios, en este segundo periodo aparecen mayormente artículos centrados en la lírica chilena ${ }^{7}$.

Otro aspecto a considerar se relaciona con el eventual acercamiento de los artículos de este periodo de la revista a los formatos y al uso del lenguaje propio de la comunicación entre comunidades científicas. A causa de las transformaciones experimentadas tras el golpe militar, la crítica académica hace uso de un lenguaje de naturaleza más conceptual y especializada en el que se intenta omitir todo tipo de digresión y exégesis personal. Con lo anterior, podría llegar a reconocerse en este tipo de escritos un estilo cercano al artículo científico o paper, el que tiene como una de sus características el uso de un lenguaje impersonal centrado en un aspecto específico de su área temática ${ }^{8}$.

6 De un total de setenta y tres artículos de la $R C h L$ que entre los años 1976 y 1980 tratan sobre autores u obras de distintas nacionalidades, veintitrés de ellos abordan literatura europea, versus dieciocho sobre literatura chilena. Los restantes veintidós artículos tratan sobre literatura latinoamericana, teniendo una especial predilección por la obra de Jorge Luis Borges, autor del cual se contabilizan alrededor de diez artículos.

De quince artículos sobre obras y autores nacionales, diez corresponden al género lírico, mientras que solo hay un artículo para una obra dramática chilena y cuatro para obras narrativas, respectivamente.

Uno de los pocos acercamientos bibliográficos a esta dimensión de la revista es el artículo titulado "La Revista Chilena de Literatura: 1970-1985", publicado en la propia $R C h L$ en el año 1991 por la docente de la Universidad de Chile Corina Rosenfeld. En este artículo, la autora da cuenta de algunos de los resultados obtenidos por parte de un proyecto de investigación en el cual se construye por primera vez una base de datos sobre artículos de la $R C h L$ publicados entre 1970 y 1985 . Entre los resultados entregados, se señala que de alrededor de doscientos artículos, ciento dieciocho cumplen tareas de conocimiento propias de la 
En términos generales, los artículos de este periodo de la $R C h L$ exhiben un predominio de la perspectiva inmanentista de análisis textual, la cual, al ocuparse exclusivamente del texto, toma distancia respecto al enfoque sociohistórico, pues establece relaciones textuales internas o del texto con categorías abstractas ajenas a todo tipo de temporalidad y/o sujeto histórico concreto. En consecuencia, a diferencia de la variedad de enfoques y metodologías presentes en la primera etapa, en esta fase son los puntos de vista estructuralistas y protosemióticos los que prevalecen en la revista.

Los artículos publicados entre 1976 y 1980 manifiestan de forma recurrente una percepción de la obra literaria acorde a la perspectiva estructuralista, en especial aquellos que abordan la lírica chilena. En estos artículos el poema se concibe como una construcción de lenguaje cuya "clave estructural... radica en su progresivo alejamiento de la realidad" (Villegas, Mitificación 40). Entendiendo el texto lírico como el resultado de una combinatoria de signos cuyas leyes estructurales son posibles de derivar, los análisis realizados se acercan hacia el terreno de la semiótica, entendida ésta como un estudio sistemático de los signos, el cual representa un tipo de crítica literaria aún más alejada de la vinculación del texto con su contexto.

Este acercamiento semiótico se evidencia en los artículos de la $R C h L$, particularmente a través de la manera cómo sus autores plantean el objetivo del análisis literario, el cual, al entender la obra como un "universo de signos", asume que para la labor crítica "la lectura ya no puede ser otra cosa que descifrar sus significados" (Pérez 124). Esta tendencia, si bien está presente en la casi totalidad de los artículos sobre poesía chilena, se reconoce particularmente en los tres artículos publicados en esta etapa de la revista que analizan la poesía de Vicente Huidobro, los cuales serán usados como ejemplos representativos de lo que sucede en el resto de los artículos de la revista centrados en la literatura chilena.

En dos de estos artículos, aparecidos durante 1977 en el número ocho de la revista, se analizan los poemas de Huidobro, "El espejo de agua" y "Sombra", respectivamente, a partir de una óptica intrínsecamente textual. En el estudio

investigación literaria, entre los cuales la descripción aparece como el propósito predominante, en especial aquel tipo de descripción a través de la cual se pretende mostrar el objeto literario desde las estructuras que lo componen basándose en un modelo "generalmente tomado del estructuralismo francés, y suelen explicitar claramente qué aspecto de la obra van a examinar, sin pretender ni un acercamiento global a ella ni un planteamiento que aproxime al lector a su esencia" (136). 
en torno al primer poema, se postula como hipótesis que el texto lírico plantea la necesidad de un desciframiento a causa de que el lenguaje poético ofrece, a través de procedimientos como la impertinencia predicativa, una sustancia transmutada diferente de las cosas existentes en la realidad (Cuneo 69). Esta percepción respecto al lenguaje de la poesía es adoptada a partir de marcos teóricos ligados a la semiótica, lo que se manifiesta a través de la aplicación de las propuestas teóricas del lingüista y crítico literario francés Jean Cohen en su texto Estructura del lenguaje poético publicado en 1966.

Dentro de las ideas propuestas por Cohen en este libro, aparece como una de las tesis fundamentales la idea de que "el poeta no habla como los demás... Su lenguaje es anormal, y esta anormalidad es la que le asegura un estilo" (cit. en Osorio, párr. 3). Cercano a los postulados de la semiótica poética y la estilística estructural ${ }^{9}$, Cohen ve en la desviación respecto al lenguaje habitual la característica fundamental del lenguaje poético. Dicha desviación, a la par que produce numerosas variantes individuales, le otorga al lenguaje de la poesía un "algo" invariable que constituye el objeto de estudio del análisis semiótico (Osorio, párr. 4).

En el caso del artículo que aborda el poema "Sombra" de Vicente Huidobro, su autora también usa como marco teórico las ideas de Cohen, para desde allí abordar las figuras de disyunción presentes en el poema, entendiéndolas como figuras que se construyen uniendo términos que habitualmente solo admiten la disyunción, con lo cual transgreden los principios lógicos del lenguaje (Invernizzi 83). El análisis se propone entonces determinar la índole y grado de la transgresión que este tipo de figuras representa, teniendo como objeto de estudio, al igual que el artículo anterior, a la desviación del lenguaje poético planteada por Cohen como rasgo fundamental de la poesía.

\footnotetext{
“Como representantes de la «estilística estructural» podrán agruparse a aquellos que creen que la lengua literaria no es distinta de la ordinaria (en donde funcionarían los signos denotativos), sino que formula sus contenidos en función de las expresiones y contenidos que caracterizan a esos signos denotativos. Éste es el punto de partida de Jean Cohen, esa dicotomía que se produce entre expresión y contenido... Las orientaciones de la investigación lingüística de este crítico encajan con los presupuestos generales de la Estilística estructural, tal y como lo pone ya de manifiesto el título de su trabajo esencial: Estructura del lenguaje poético, de 1966, un estudio que intenta determinar la «naturaleza poética» de la poesía. Considera tarea prioritaria apuntar cuáles son las formas poéticas del lenguaje, sin más, y teniendo en cuenta el doble nivel que constituye ese lenguaje: expresión y contenido, o planos fónico y semántico" (Gómez Redondo, párr. 5-6).
} 
Otro de los artículos que aborda la obra de Huidobro es "Altazor: hacia una verticalización de la épica" de la autora Berta López, aparecido durante 1979 en el número catorce de la revista. En este estudio también se hace uso de los planteamientos de Cohen, señalando que "el análisis de las 'figuras' o desviaciones que aparecen en el referido poema está basado en los postulados que sustenta Jean Cohen en su libro La estructura del lenguaje poético" (24). Lo que sostiene este artículo es una visión épica de lo vivido por Altazor, la que se plantea como vertical al ser la caída el eje en que se estructura el poema. El objetivo del análisis es entonces mostrar "cómo el mayor grado de desviación del sentido de la palabra respecto del código usual refleja el proceso de verticalización que se opera en la épica" (38).

De acuerdo con las reflexiones de Bernardo Subercaseaux respecto a la crítica literaria chilena realizada después de 1973, el análisis realizado por Brenda López sobre Altazor tiende a lo que se califica como una "fetichización del texto", de la cual este artículo sería "un ejemplo extremo" (Transformaciones 18). Para Subercaseaux, este tipo de crítica tiende a la fetichización del texto "debido a que lo supone como una entidad significante siempre idéntica a sí misma, y porque focaliza la articulación de la obra desde una perspectiva centrípeta, practicando una suerte de microanálisis que cierra toda posibilidad de conexión o cruce de ese texto con otros códigos (o lecturas) mayores" (Transformaciones 18).

\section{CONCLUSIÓN}

Frente al predominio de teorías inmanentistas durante los primeros años de dictadura militar, más allá de quedarse en la duda si esto responde o no a una autocensura por parte de los críticos, es importante evaluar el eventual acercamiento en este periodo de la $R C h L$ a los formatos y al uso del lenguaje propios de la comunicación entre comunidades científicas. Por otra parte, lo anterior implica también entender los cambios experimentados por la revista como un tipo de estrategia que le permite no solo romper un silencio de tres años, sino, además, resituarse en el reducido ámbito académico y científico nacional de ese momento.

A partir de la idea de que "como género, un artículo de investigación siempre cumple la función de reivindicar un conjunto de conocimientos, en tanto se trata de defender y sustentar una forma particular de construir y abordar un objeto de estudio" (Sabaj et al. 70), en esta segunda fase de la 
revista, el uso de un lenguaje más conceptual, junto con el planteamiento de objetivos mucho más técnicos para el análisis literario, apunta a posicionar los estudios y la crítica literaria como un área del saber cuyo nivel de especialización la pone a la par de los ámbitos tecnológicos y científicos mayormente valorados en ese entonces.

A pesar de reducir la variedad de enfoques y de aislar la obra literaria respecto a otros discursos y contextos, los artículos de esta etapa, al manifestar el manejo de un saber teórico-metodológico especializado, efectuando un tipo de análisis particular de su objeto de estudio, pueden ser entendidos como un tipo de "reivindicación epistémica":

Una reivindicación epistémica es el acto a través del cual un actor sitúa socialmente el saber que utiliza. Este acto de posicionamiento social del saber...contiene principalmente dos dimensiones: una política y otra constitutiva (o instituyente). La dimensión política responde a la necesidad que tiene un actor de definir su propio estatus de conocedor, es decir, de conquistar una cierta autoridad epistémica que le permita controlar lo que debe saberse. No se trata únicamente de definir el conocimiento apropiado, sino también-y sobre todo- de desarrollar la confianza y la legitimidad que hacen posible que un saber sea considerado pertinente (Sabaj et al. 71).

Considerando la situación en que se encuentra el campo académico posterior a 1973, dentro del cual las humanidades resultan fuertemente intervenidas y cuestionadas, los cambios experimentados por la $R C h L$ respecto a sus primeros años pueden entenderse como un intento por reivindicar un área del saber que se encuentra debilitada. El esfuerzo por profesionalizar los estudios literarios y otorgarles validez y pertinencia como área del saber pueden verse como una estrategia para legitimar la autoridad y autonomía intelectual de sus conocedores en medio de un campo académico estrictamente controlado.

Si durante 1970 hasta 1972 la $R C h L$ da cuenta de los distintos enfoques teóricos y metodológicos presentes en el proceso de modernización de la crítica literaria chilena participando con ello de la diversidad propia del campo cultural y académico de la Unidad Popular, en esta segunda etapa, la prevalencia de un solo enfoque centrado en el texto literario y sus aspectos específicos responde a la modificación de ese campo cultural en el cual el mundo académico es constreñido y desvinculado del resto de la vida social. Encerrado sobre sí mismo, el campo académico vive una obligada fase de especialización, que, en el caso de la crítica literaria, se traduce en el 
predominio de una perspectiva inmanentista en el análisis literario, la que, si bien significa un retroceso respecto al nivel alcanzado antes de 1973, también permite dar continuidad a la labor crítica en medio de un contexto en que la propia palabra "crítica" resulta poco admisible.

La permanencia de la $R C h L$ hasta la actualidad es una señal de continuidad en la senda de profesionalizar e insertar los estudios literarios en el complejo campo científico latinoamericano. Frente a lo anterior, las nuevas tareas para la crítica literaria dicen relación no solo con diversificar sus formatos de escritura, sino, especialmente, con repensar las vías a través de las cuales el trabajo del intelectual se inserta en el espacio público, ejerciendo allí la labor crítica que, sin duda, le es inherente a las humanidades como área del saber.

\section{BIBLIOGRAFÍA}

Allende, Salvador et al. Programa Básico de la Unidad Popular. Santiago de Chile: Instituto Geográfico Militar, 1970. Web. 17. jul. 2018. <http://www.memoriachilena.cl/602/w3article-7738.html>

Beigel, Fernanda. "Las revistas culturales como documentos de la historia latinoamericana". Utopía y Praxis Latinoamericana. Revista Internacional de Filosofia Iberoamericana y Teoría Social 8 / 20 (2003): 105-115. Impreso.

Bourdieu, Pierre. "Campo científico". Intelectuales, politica y poder. Trad, Alicia Gutiérrez. Buenos Aires: Eudeba, 2000. 75-110. Impreso.

Canto, Nadinne. "El lugar de la cultura en la vía chilena al socialismo. Notas sobre el proyecto estético de la Unidad Popular". Revista Pléyade 9 (2012): 153-178. Web. 8. jun.2018.<http:// www.academia.edu/4003113/El_lugar_de_la_cultura_en_la_v\%C3\%ADa_chilena_al_ socialismo._Notas_sobre_el_proyecto_est\%C3\%A9tico_de_la_Unidad_Popular $>$

Casali, Aldo. "Reforma universitaria en Chile, 1967-1973. Pre-balance histórico de una experiencia frustrada". Intus-Legere Historia 5/1 (2011): 81-101. Web. 18. jul. 2018. $<$ http://intushistoria.uai.cl/index.php/intushistoria/article/viewFile/83/75>

Cohen, Jean. Estructura del lenguaje poético. Madrid: Gredos, 1973 [1966].

Cuneo, Ana María. “Análisis de 'El espejo de agua', poema de Vicente Huidobro". Revista Chilena de Literatura 8 (1977): 67-82. Impreso.

Dorfman, Ariel. "El patas de perro no es tranquilidad para mañana". Revista Chilena de Literatura 2-3 (1970): 167-197. Impreso.

Eichenbaum, B. "La teoría del método formal”. Teoría de la literatura de los formalistas rusos. Trad. Ana María Nethol. México D. F.: Siglo XXI Editores S. A., 1978. 21-54. Impreso.

Goic, Cedomil. "Poética del exordio en La Araucana". Revista Chilena de Literatura 1 (1970): 5-22. Impreso.

"Re: Revista Chilena de Literatura". 18 abril 2018. E-mail. 
Gómez Redondo, Fernando. "Definición de estilística estructural”. Web. 04. Sept. $2018<$ http:// www.lahistoriaconmapas.com/historia/historia2/definicion-de-estilistica-estructural/>

Hauser, Arnold. "5. La crítica de arte”. Sociología del arte (4. Sociología del público). Trad. Vicente Romano. Barcelona: Editorial Labor S. A., 1977. 600-621. Impreso.

Invernizzi, Lucía. "Figuras de disyunción en 'Sombra' de Vicente Huidobro". Revista Chilena de Literatura 8 (1977): 83-107. Impreso.

López, Berta. “Altazor: hacia una verticalización de la épica”. Revista Chilena de Literatura 14 (1979): 24-54. Impreso.

Mendoza, Sara y Tatiana Paravic. "Origen, clasificación y desafíos de las revistas científicas". Investigación y Postgrado 21 / 1 (2006): 49-75. Impreso.

Osorio, Gustavo. "Jean Cohen y el análisis del texto poético: Isopatetismo". Web. 4 sep. $2018<$ http://circulodepoesia.com/2011/06/jean-cohen-y-el-analisis-del-texto-poeticoisopatetismo/>

Pérez, Floridor. "Para una lectura de la Poesía de Gonzalo Rojas". Revista Chilena de Literatura 13 (1979): 117-141. Impreso.

Rosenfeld, Corina. "La Revista Chilena de Literatura: 1970- 1985". Revista Chilena de Literatura 38 (1991): 127-158. Impreso.

Sabaj, Omar et al. "Estrategias académicas de inserción científica: una propuesta metodológica para el estudio de las reivindicaciones epistémicas en los artículos de investigación". Revista Innovar 23/48 (2013): 67-82. Web. 8 jun. $2018<\mathrm{https}$ ://www.academia.edu/29681851//>

Sarlo, Beatriz. "Intelectuales y revistas: razones de una práctica". Cahiers du CRICCAL 9-10: Le discourse culturel dans le revue latino-americaines de 1940 à 1970. Paris: Presses de la Sorbonne Nouvelle- Paris III (1992): 9-16. Impreso.

Schwartz, Jorge y Roxana Patiño. “Introducción”. Revista Iberoamericana LXX/208-209 (2004): 647-650. Impreso.

Schopf, Federico. "La escritura de la semejanza en Nicanor Parra". Revista Chilena de Literatura 2-3 (1970): 43-132. Impreso.

Skármeta, Antonio. "El motivo de oposición entre aldea y ciudad en dos dramas chilenos". Revista Chilena de Literatura 1 (1970): 31-41. Impreso.

Subercaseaux, Bernardo. "Historia 'personal' de la crítica literaria en Chile". Revista Dossier. Croquis/Dossier 4, pp. 1-13. Web. 21. jul. 2018. <http://www.revistadossier.cl/historiapersonal-de-la-critica-literaria-en-chile>

Transformaciones de la crítica literaria en Chile: 1960-1982. Santiago de Chile: CENECA, 1982. Impreso.

Todorov, Tzvetan. "Presentación". Teoría de la literatura de los formalistas rusos. Trad. Ana María Nethol. México D. F.: Siglo XXI Editores S. A., 1978. 11-20. Impreso.

Valderrama, José. "La publicación en revistas especializadas. Un recurso estratégico en la investigación científica y tecnológica". Los laberintos del futuro. Ciencia y tecnología en América Latina. Santa Fe: Ediciones de la Universidad Nacional del Litoral, 2001. 1-24. Web. 28 jun. 2018. <http://prodicyt.org/publicaciones/20120113011001.pdf>

Villegas, Juan. "Mitificación de la anécdota amorosa en un poema de Gabriela Mistral". Revista Chilena de Literatura 7 (1976): 37-45. Impreso. 